\title{
Major components of metabolic syndrome and nutritional intakes in different genotype of UCP2 -866G/A gene polymorphisms in patients with NAFLD
}

\author{
Mahdieh Abbasalizad Farhangi ${ }^{*}$, Fatemeh Mohseni ${ }^{2}$, Safar Farajnia ${ }^{2}$ and Mohammad-Asghari Jafarabadi ${ }^{3}$
}

\begin{abstract}
Background: It has been suggested that dietary modifications in combination with genetic predisposition play an important role in the pathogenesis of NAFLD. In the current study we aimed to investigate the major components of metabolic syndrome in patients with non-alcoholic fatty liver disease (NAFLD) and nutritional intakes according to different genotype of uncoupling protein-2 (UCP2) -866G/A gene polymorphism in these patients.

Methods: In this study 151 participants including 75 patients with NAFLD and 76 healthy individuals were enrolled. Dietary intakes were assessed using a semi-quantitative food-frequency questionnaire. Physical activity was obtained by metabolic equivalent questionnaire. Anthropometric assessments were conducted by a trained researcher and body mass index and waist to hip ratio were calculated. Body composition was measured by bioelectrical impedance analysis and biochemical assays including fasting serum glucose, liver enzymes and lipid profiles were measured. Polymorphisms of -866G/A UCP2 gene was determined using polymerase chain reaction-restriction fragment length polymorphism method.

Results: Serum triglyceride concentrations in $53.3 \%$ of NAFLD patients compared with $35.5 \%$ of control group was more than $150 \mathrm{mg} / \mathrm{dl}(P=0.034)$. A significantly higher prevalence of low serum high density lipoprotein cholesterol concentrations was also observed in female NAFLD patients $(P<0.001)$. Dietary intakes in NAFLD group were not significantly different compared with control group $(P>0.05)$. However, according to genotypes patients with AG genotype had significantly higher protein consumption compared with control group $(P<0.05)$. Significantly higher consumption of dietary iron and copper in NAFLD patients with AG genotype was only observed among patients with NAFLD. However, the comparison of macro and micronutrient intakes in control group sound for stronger differences for AA genotype although these differences did not achieve significant threshold.
\end{abstract}

Conclusions: A high prevalence of metabolic abnormalities was reported among NAFLD patients. Additionally, among NAFLD group, patients with AG genotype significantly consumed more protein, iron and copper in their usual diet.

Keywords: Uncoupling protein 2 (UCP2) gene, -866G/A polymorphism, Nonalcoholic fatty liver disease (NAFLD), Nutrition

\footnotetext{
*Correspondence: abbasalizad_m@yahoo.com; abbasalizadfarhangim@ gmail.com

${ }^{1}$ Nutrition Research Center, Department of Community Nutrition, School

of Nutrition, Tabriz University of Medical Sciences, Tabriz, Iran

Full list of author information is available at the end of the article
} 


\section{Background}

Nonalcoholic fatty liver disease (NAFLD) is defined as abnormal lipid deposition in the hepatocytes in the absence of significant amount of alcohol intake. NAFLD includes nonalcoholic steatohepatitis (NASH) associated with markedly increased risk of cardiovascular and liverrelated mortality which finally progress to more severe forms of liver disease such as advanced fibrosis, cirrhosis and even hepatocellular carcinoma [1,2].

In developed countries, the prevalence of the NAFLD is up to $30 \%$ in the general population, $50 \%$ in patients with type 2 diabetes mellitus (T2DM), $76 \%$ in obese people and almost $100 \%$ in patients with morbid obesity [3, 4]. According to data from the US National Health and Nutrition Examination Survey (NHANES) report, the prevalence of NAFLD has increased from 47 to $75 \%$ between 1988 and 2008 [5, 6]. In a large populationbased study in southern regions of Iran in 2011, $21.5 \%$ the prevalence of NAFLD in the adult general population was reported [5].

In addition to genetic predisposition, change in lifestyles and dietary habits increases the prevalence of obesity, diabetes mellitus, metabolic syndrome, cardiovascular disease and their consequences such as NAFLD throughout the world [7-9]. The long-term excessive food intake and dietary composition in food groups, macronutrients and micronutrients is associated with progression of NAFLD mostly recognized by abnormal ultrasonography (US) findings or elevated alanine aminotransferase (ALT) and aspartate aminotransferase (AST) concentrations as markers of liver injury [10, 11]. In general, lower antioxidant consumption, higher intake of calorie, carbohydrate, protein and high dietary cholesterol stimulate hepatic lipid accumulation leading to development of fatty liver disease [12-14]. In addition, inadequate intake of micronutrients, copper and iron may also be involved in pathogenesis of NAFLD [15]. NAFLD symptoms manifested by abnormalities in serum and hepatic stores of copper and iron in rodent models $[16,17]$ and low hepatic copper levels is known to be correlated with NAFLD progression and components of metabolic syndrome [16, 17]. However no report of the association between dietary intakes of these micronutrients and different genotypes of UCP2 in NAFLD is available. Additionally, oxidative stress has been involved in the pathogenesis of NAFLD; vitamin C and E are wellknown antioxidants capable in blocking distribution of radical reactions [18]. These antioxidants play important roles in histological improvement of inflammation in NAFLD $[18,19]$.

Dietary recommendation should be appropriate according to an individual status and even genetic background [20]. Several studies mostly in animal models introduced diet as a potent modifier of NAFLD-related genes expression [10]; for example enhanced $\omega-6 / \omega-3$ poly unsaturated fatty acids (PUFAs) ratio interacts with PNPLA3 rs738409 gene in the GG homozygote and enhances ALT concentrations and hepatic fat accumulation in human [21]. Other studies also revealed the role of $\omega-3$ fatty acids as regulators of hepatic gene expression by mainly aiming the transcription factors sterol regulatory element binding transcription factor 1 (SREBP-1c) and down-regulating inflammatory genes [22].

Three common polymorphisms in uncoupling protein 2 (UCP2) are $-866 \mathrm{G}>\mathrm{A}$ (rs659366), 55 Ala/Val (rs660339) and 3-UTR ins > del [23]. The relationship of $-866 \mathrm{G}>\mathrm{A}$ gene polymorphism of UCP2 (rs659366) with obesity and type 2 diabetes has been reported previously [23]. UCP2 is located in the inner membrane of mitochondria, acts as a mediator of proton leak and ultimately leads to decreased ATP production and energy release [24]. The wide tissue distribution of UCP2 shows its potent role in several pathologic events on specific tissue or organs [25, 26]. Enhanced UCP2 expression is able to respond oxidative stress by controlling production of mitochondrial superoxide [26]; therefore, it may be a therapeutic target for management of oxidative damage and metabolic imbalance in NAFLD [25].

Considering the lack of knowledge about the interaction between UCP2 gene polymorphism and nutrient intakes in NAFLD patients we aimed to investigate the interaction between energy and nutrients intake and $-866 \mathrm{G}>\mathrm{A}$ gene polymorphism of uncoupling protein 2 (UCP2) in patients with NAFLD.

\section{Methods}

The present case control study was conducted among 75 patients with NAFLD and 76 healthy individuals; these two groups were matched by age and gender with group matching. Patients were recruited from the out patients gastroenterology clinics of Tabriz University of Medical Sciences. Disease diagnosis was confirmed by a physician based on the findings of ultrasonography (US). Written informed consent was obtained from all of subjects before participation in the study. The protocol of the study has been approved by the ethics committee of Tabriz University of Medical Science (Registration Code: 11013).

Inclusion criteria were as follows: aged between 20 and 50 years old, BMI between 25 and $39.9 \mathrm{~kg} / \mathrm{m}^{2}$. The exclusion criteria were: any history of acute or chronic liver diseases, viral hepatitis, hemochromatosis, Wilson's disease, autoimmune or endocrine disorders, pregnancy or lactation, alcohol consumption, using hepatotoxic medications including corticosteroids, amiodarone, valproate and being on weight loss diets for at least 3 months prior participation in study. 


\section{Anthropometric assessments}

Weight was measured with a calibrated scale (SECA, Hamburg, Germany) to the nearest $0.1 \mathrm{~kg}$ with the minimal clothing without shoes and height using a non-stretchable measurement tape with the precision of $0.1 \mathrm{~cm}$. The measurements were taken one time by a trained researcher. The body mass index (BMI) was calculated as weight $(\mathrm{kg})$ divided by height squared $\left(\mathrm{m}^{2}\right)$. Waist circumference (WC) was measured in standing position at the level of the umbilicus and hip circumference $(\mathrm{HC})$ was measured at the maximum point between the hip and the buttock with a non-elastic tape.

\section{Physical activity level}

Physical activity was obtained by the questionnaire with nine different metabolic equivalent (MET) scales ranging from sleep/rest (0.9 METs) to high-intensity physical activities ( $>6$ METs) [27]. This questionnaire has been validated among Iranian people [28] and evaluates usual daily physical activity by simple self-reported values. The precision of this tool is comparable with the findings of international physical activity questionnaire (IPAQ) [27].

For each activity level, the MET value was multiplied by the time spent at that particular level. The MET-time at each level was added to obtain a total over $24 \mathrm{~h}$ METtime, representing the physical activity level on an average weekday. Physical activities of different intensities were categorized to sedentary (<3 METs), moderate (3-6 METs) and vigorous (>6 METs) respectively [27].

\section{Biochemical assessments}

After an overnight fasting, all of patients underwent a laboratory examination. Venous blood samples were taken from individuals and approximately $2 \mathrm{cc}$ of the blood was transferred into tubes containing ethylene di-amine tetra acetic acid (EDTA) for genetic assays. Sera were also extracted from remaining blood samples for biochemical assays including fasting serum glucose (FSG), ALT, AST, total cholesterol (TC), triglyceride (TG) and high density lipoprotein cholesterol (HDLC). Laboratory assessments were performed by Abbott ALCYON $^{\mathrm{TM}} 300$ auto analyzer using commercial ELISA kits (Pars-Azmoon, Tehran, Iran). All of the biochemical assays were performed by a trained lab assistant who was blinded to group assignments. Serum low density lipoprotein cholesterol (LDL-C) was calculated by Friedewald formula: LDL-C $=\mathrm{TC}-(\mathrm{HDL}-\mathrm{C}-\mathrm{TG} / 5)$ [29].

Biochemical parameters were also categorized according to the National Cholesterol Education Program's Adult Treatment Panel III report (NCEP-ATP III) criteria [30] (except for waist circumference which was defined as $\geq 90 \mathrm{~cm}$ for both genders for Iranian population) for defining metabolic abnormalities [31, 32].

\section{Dietary intake}

Dietary intakes were assessed using a semi-quantitative food-frequency questionnaire (FFQ) adapted to the Iranian society [33]. Since the efficiency of a FFQ is related to the culture and ethnic background of the study population, the validity and reliability should be conducted in different population [34]. The FFQ included 168 food items with specified serving sizes commonly consumed by Iranians. Participants reported their average frequency intake of each food item in terms of the number of specified serving sizes consumed per day/week/month/year, or never. The reported frequency of consumed foods and portion sizes for each food item were converted to a daily intake.

\section{Body composition analysis}

Fat mass (FM) and fat free mass (FFM) were determined using a Bioelectrical Impedance Analysis (BIA; Tanita BC-418, Tanita Corp., Tokyo, Japan). Analysis were carried out for all subjects after $12 \mathrm{~h}$ of fasting period while individuals wore light clothes, no shoes, no jewellery and no heavy physical activity and alcohol consumption or diuretic intake prior to analysis [35].

\section{DNA extraction and genotyping}

Genomic DNA was extracted from the blood cells by salting out method [36]. This technique is a simple deproteinization cell procedure by dehydration and precipitation with saturated $\mathrm{NaCl}$ solution. Single nucleotide gene polymorphism (SNP) was detected by polymerase chain reaction-restriction fragment length polymorphisms (PCR-RFLP) method. DNA fragment analogous to -866 A/G polymorphism (rs659366) in UCP2 gene was amplified by $5^{\prime}$-CACGCTGCTTCTGCCAGGAC-3' as forward primer and 5'-AGGCGTCAGGAGATGGACCG-3' and a reverse primer. $1 \mu$ Genomic DNA in addition to $0.2 \mu$ Taq DNA polymerase and $1 \mu$ of each primer were added to $22 \mu$ of $1 \times$ PCR master-mix. PCR conditions were: a primary denaturation at $95{ }^{\circ} \mathrm{C}$ for 5 min followed by 38 cycles of denaturation at $94{ }^{\circ} \mathrm{C}$ for $1 \mathrm{~min}$; annealing at $59{ }^{\circ} \mathrm{C}$ for $1 \mathrm{~min}$; extension at $72{ }^{\circ} \mathrm{C}$ for $46 \mathrm{~s}$ and a final extension at $72{ }^{\circ} \mathrm{C}$ for $5 \mathrm{~min}$. The PCR products were run for visualization on $1 \%$ agarose gel and stained by ethidiumbromide. $10 \mu$ of PCR products were digested by $0.3 \mu$ $M L U I$ restriction enzyme, incubated at $37{ }^{\circ} \mathrm{C}$ for $1.5 \mathrm{~h}$ and ultimately separated on $2 \%$ agarose gel electrophoresis. The (-866) AA genotype was indicated by a single 369 base-pair (bp) fragment as result of loss of MluI site, whereas, the wild-type (-866) GG genotype was digested into 297 and 72 bp fragments (Fig. 1). 


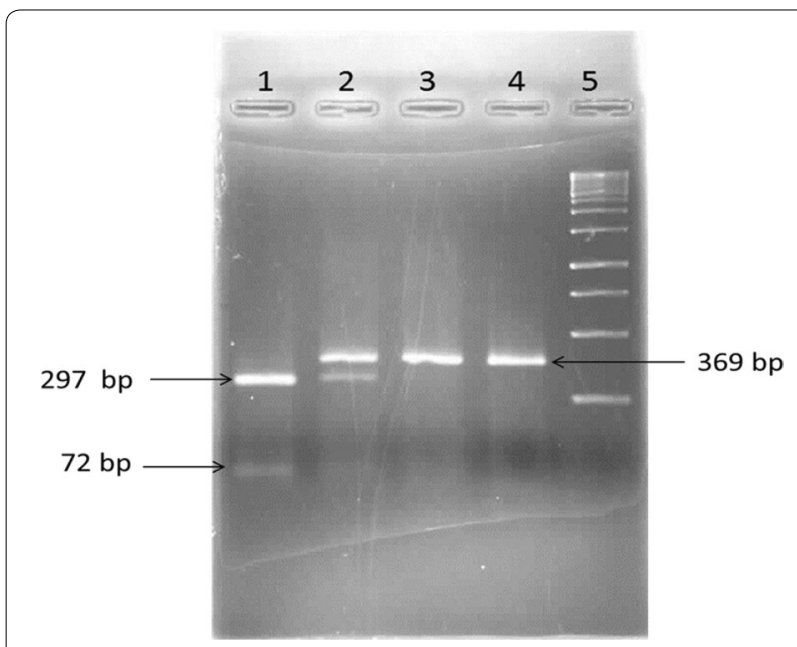

Fig. 1 PCR-RFLP analysis for UCP2 -866G/A polymorphism. Lane 1 GG genotype. Lane 2 AG genotype. Lane 3 AA genotype. Lane 4 Undigested PCR product. Lane 5 DNA size marker

\section{Statistical methods}

The SPSS statistical software package version 16 (SPSS Inc., Chicago, IL, USA) was used for all statistical analyses. Kolmogorov-Smirnov test was performed for normality of the distributions of variables. Demographic characteristics, energy intake and nutrients intake of the two groups were compared by means of analysis of covariance (ANCOVA) and one way ANOVA tests. The Chi Square test and student's $t$ test were used for comparison of categorical and continuous variables between groups respectively. $P$ values lower than 0.05 has been considered to be statistically significant.

\section{Results}

The demographic, anthropometric and biochemical parameters of the study population are presented in Table 1. No significant difference was observed in mean age, BMI and fat free mass between NAFLD and control groups; However, WC and WHR in NAFLD patients were significantly higher compared with healthy group $(P<0.05)$. Among biochemical variables, serum HDL-C and LDL-C concentrations were significantly lower and serum AST, ALT and TG concentrations were significantly higher in NAFLD patients compared with control group $(P<0.05$ and $P<0.01$ respectively). Table 2 presents the prevalence of several components of metabolic syndrome according to ATP III criteria; significantly higher prevalence of $\mathrm{WC} \geq 90 \mathrm{~cm}$ was observed in patients with NAFLD compared with control group $(P=0.037)$. Approximately $53.3 \%$ of NAFLD patients compared with $35.5 \%$ of control group had TG $\geq 150 \mathrm{mg} / \mathrm{dl}(P=0.034)$. A significantly higher prevalence of low serum HDL-C concentrations was also observed in female NAFLD patients $(P=0.001)$.

Mean energy and protein intake in NAFLD group was higher and vitamin $C$ and $E$ intake were lower in NAFLD patients compared with control group. However statistical significance was not achieved (Table 3).

The comparison of dietary intakes according to $-866 \mathrm{~A} / \mathrm{G}$ of UCP2 gene polymorphism between case and control groups is presented in Table 4. Patients in AG genotype have significantly higher protein consumption compared with control group $(P<0.05)$. Also patients in this genotype have significantly higher carbohydrate, iron and copper consumption in comparison of patients in other genotypes $(P<0.05)$. No significant difference was observed for other nutrients.

\section{Discussion}

In the current case-control study, we demonstrated a higher dietary intake of protein, carbohydrate, iron and copper in the AG genotype of UCP2 gene polymorphisms in patients with NAFLD. These patients had also higher values of central obesity indices and metabolic abnormalities compared with healthy individuals. In our review of the literature, this is the first report evaluating the association between 866A/G UCP2 gene polymorphism and nutritional intakes in patients with NAFLD. Our results showed a higher intake of energy and protein among NAFLD patients compared with healthy control subjects.

Consistent with our findings, Zelber-Sagi et al. [37] and Silva et al. [38] reported higher consumption of energy and protein in patients with NAFLD. HashemiKhani et al. [12] reported a significantly higher amount of carbohydrate and fat intake and no significant higher consumption of protein among one hundred NAFLD patients compared with healthy individuals. Interestingly they also reported a lower nutrient adequacy ratio (NAR) as an index of dietary quality in these patients $(P<0.05)$. We did not achieve significant threshold in our energy and nutrient intakes values probably because of our lower sample size or difference in disease stage compared with these studies. The higher energy and carbohydrate intake would finally lead to anthropometric and metabolic abnormalities as confirmed in the current study; waist circumference as an index of central obesity and metabolic syndrome [39] was higher in our NAFLD group. Also higher serum aminotransferase concentrations and a significantly high prevalence of metabolic syndrome components including elevated serum TG and low serum HDL-C concentrations were also reported in our NAFLD patients. In Clark et al. study [40] there was a significant association between high aminotransferase and WC and higher BMI in NAFLD patients. Rocha et al. 
Table 1 General characteristics of study subjects

\begin{tabular}{|c|c|c|c|c|}
\hline Variable & NAFLD $(N=75)$ & Control $(\mathrm{N}=76)$ & Mean difference (95 \% Cl) & $P^{*}$ \\
\hline \multicolumn{5}{|l|}{ Sex } \\
\hline Male [n (\%)] & $36(48 \%)$ & $29(38.2 \%)$ & - & 0.25 \\
\hline Female [n (\%)] & $39(52 \%)$ & $47(61.8 \%)$ & - & \\
\hline Age (years) & $40.65(8.41)$ & $38.87(8.2)$ & $1.78(-0.89$ to 4.46$)$ & 0.18 \\
\hline BMI $\left(\mathrm{kg} / \mathrm{m}^{2}\right)$ & $31.78(4.17)$ & $31.38(4.04)$ & $0.40(-0.92$ to 1.72$)$ & 0.54 \\
\hline WC (cm) & $103.12(9.46)$ & $100.14(8.72)$ & 2.98 (0.55 to 5.90$)$ & 0.04 \\
\hline WHR & $0.92(0.06)$ & $0.89(0.06)$ & 0.02 (0.002 to 0.04$)$ & 0.03 \\
\hline BMR (kcal/day) & $1739.64(290.53)$ & $1679(96.31)$ & $60.64(-33.74$ to 155.02$)$ & 0.20 \\
\hline FM (\%) & $32.67(8.58)$ & $34.57(8.02)$ & $-1.90(-4.57$ to 0.76$)$ & 0.16 \\
\hline FFM (\%) & $67.06(8.11)$ & $65.51(7.84)$ & $-1.55(-4.11$ to 1.02$)$ & 0.23 \\
\hline $\mathrm{TC}(\mathrm{mg} / \mathrm{dl})$ & $183.44(36.91)$ & $187.96(28.89)$ & $-4.52(-15.17$ to 6.13$)$ & 0.40 \\
\hline $\mathrm{HDL}-\mathrm{C}(\mathrm{mg} / \mathrm{dl})$ & $43.24(11.4)$ & $48.29(11.6)$ & $-5.05(-8.75$ to -1.35$)$ & 0.008 \\
\hline LDL-C (mg/dl) & $104.11(34.62)$ & $111.52(26.43)$ & -6.81 ( -16.71 to 3.09$)$ & 0.03 \\
\hline FSG (mg/dl) & $90.59(11.24)$ & 89.59 (9.93) & $0.63(-2.78$ to 4.03$)$ & 0.71 \\
\hline ALT (IU/I) & 49.96 (25.958) & $26.84(9.814)$ & $23.12(16.82$ to 29.41$)$ & $<0.001$ \\
\hline AST (IU/I) & $32.99(14.86)$ & $23.08(6.12)$ & 9.91 (6.26 to 13.55$)$ & $<0.001$ \\
\hline $\mathrm{TG}(\mathrm{mg} / \mathrm{dl})$ & $152.00(114.00-225.00)$ & 118.50 (79.50-198.00) & - & 0.004 \\
\hline Physical activity & & & & 0.56 \\
\hline MET: 3-6 & $62(82.7 \%)$ & $60(78.9 \%)$ & - & \\
\hline MET $>6$ & $13(17.3 \%)$ & $16(21.1 \%)$ & - & \\
\hline
\end{tabular}

Italic values are statistically significant at $\mathrm{P}<0.05$

$B M I$ body mass index, WC waist circumference, WHR waist to hip ratio, BMR basal metabolic rate, FM fat mass, FFM fat free mass, FSG fasting serum glucose, TC total cholesterol, TG triglyceride, HDL-C high density cholesterol, $L D L-C$ low density cholesterol, $A L T$ alanine amino transferase, $A S T$ aspartate amino transferase, MET metabolic equivalent

* P value for sex, physical activity and TG based on Chi Square tests and U Mann-Whitney respectively; otherwise based on independent $t$ test using equal variable. TG are presented based on median (percentile 25th-percentile 75th) and other variables data are presented based on mean (SD)

Table 2 The prevalence of several components of metabolic syndrome according to the National Cholesterol Education Program's Adult Treatment Panel (ATP) III criteria [30, 31]

\begin{tabular}{llll}
\hline Variable & NAFLD $(\mathbf{N}=\mathbf{7 5})[\mathbf{n}(\%)]$ & Control $(\mathbf{N}=\mathbf{7 6})[\mathbf{n}(\%)]$ & $P^{*}$ \\
\hline$W C(\mathrm{~cm}) \geq 90 \mathrm{~cm}$ & $71(94.7)$ & $64(84.2)$ & $1(1.3)$ \\
FSG $(\mathrm{mg} / \mathrm{dl}) \geq 110 \mathrm{mg} / \mathrm{dl}$ & $2(2.7)$ & $27(35.5)$ & 0.03 \\
$\mathrm{TG}(\mathrm{mg} / \mathrm{dl}) \geq 150 \mathrm{mg} / \mathrm{dl}$ & $40(53.3)$ & $13(44.8)$ & 0.55 \\
$\mathrm{HDL}-\mathrm{C}(\mathrm{mg} / \mathrm{dl})<40 \mathrm{mg} / \mathrm{dl}$ (male) & $18(50)$ & $18(38.3)$ & 0.03 \\
$\mathrm{HDL}-\mathrm{C}(\mathrm{mg} / \mathrm{dl})<50 \mathrm{mg} / \mathrm{dl}$ (female) & $24(61.5)$ & 0.08 \\
\hline
\end{tabular}

Italic values are statistically significant at $\mathrm{P}<0.05$

WC waist circumference, FSG fasting serum glucose, TG triglyceride, HDL-C high density cholesterol

* Based on Chi Square test

[2] also reported a strong association between high WC and components of metabolic syndrome in patients with NAFLD $(P<0.001)$. Elevated serum aminotransferase concentrations have been associated with general and central obesity indices and elevated triglyceride concentrations in these patients $[2,40]$.

Interestingly, we reported a significantly higher consumption of dietary iron and copper in AG genotype of UCP2 gene polymorphisms in patients with NAFLD.
This difference was only observed among patients with NAFLD and not in control group. However, the comparison of macro and micronutrient intakes in control group sounds for stronger differences for AA genotype. This finding further confirms the possible role of AG genotype-nutrient interaction in pathogenesis NAFLD.

Similar finding was also reported by Silva et al. [38]; however unlike our study, no interaction between dietary intakes and gene polymorphisms has been evaluated in 
Table 3 Comparison of energy, macro and micronutrient intakes between study groups

\begin{tabular}{|c|c|c|c|c|}
\hline & NAFLD $(N=75)$ & Control $(\mathrm{N}=76)$ & Mean difference $(95 \% \mathrm{Cl})$ & $P$ \\
\hline Calories (kcal) & $2815.06(536.35)$ & $2794.93(448.64)$ & $-20.13(-179.29$ to 139.03$)$ & 0.80 \\
\hline Protein (g/day) & $93.88(21.62)$ & $88.88(16.60)$ & $-4.99(-11.20$ to 1.20$)$ & 0.11 \\
\hline Carbohydrate (g/day) & 437.38 (89.72) & 438.49 (79.58) & $1.10(-26.18$ to 28.39$)$ & 0.93 \\
\hline Total fat (g/day) & $89.70(27.03)$ & $91.52(24.35)$ & $1.82(-6.45$ to 10.10$)$ & 0.66 \\
\hline Vitamin E (mg/day) & $14.08(5.60)$ & $14.63(4.11)$ & $0.80(-1.03$ to 2.12$)$ & 0.49 \\
\hline Vitamin C (mg/day) & 124.18 (83.70-165.06) & $116.71(90.06-177.29)$ & - & 0.84 \\
\hline Iron (mg/day) & $23.37(6.04)$ & $22.86(5.04)$ & $0.90(-2.30$ to 1.27$)$ & 0.56 \\
\hline Copper (mg/day) & $2.29(0.48)$ & $2.30(0.53)$ & $-0.004(-0.16$ to 0.16$)$ & 0.95 \\
\hline
\end{tabular}

All of data are presented as mean (SD) except for the Vitamin C intake which is presented as median (percentile 25th-percentile 75th). P value of Vitamin E and C based on U Mann-Whitney and for other variables as independent sample $t$ test

Table 4 The comparison of energy, macro and micronutrient intakes according to -866A/G of UCP2 gene polymorphism between study groups

\begin{tabular}{|c|c|c|c|c|c|}
\hline Variable & Genotype & NAFLD $(N=75)$ & Control $(\mathrm{N}=76)$ & Mean difference $(95 \% \mathrm{Cl})$ & $P^{\dagger}$ \\
\hline \multirow[t]{3}{*}{ Calories (kcal/day) } & $A A$ & $2674.88(774.39)$ & $3089.64(342.12)$ & $-431.75(-2515.28$ to 1651.79$)$ & 0.61 \\
\hline & $A G$ & $2920.76(496.14)$ & $2852.15(425.28)$ & $6.23(-200.83$ to 213.28$)$ & 0.95 \\
\hline & GG & $2672.68(534.37)$ & $2708.95(467.26)$ & $-29.76(-241.50$ to 181.97$)$ & 0.78 \\
\hline$p^{\ddagger}$ & & 0.14 & 0.16 & & \\
\hline \multirow[t]{3}{*}{ Fat (g/day) } & $A A$ & $96.22(46.68)$ & $96.67(15.87)$ & $-12.64(-127.33$ to 102.04$)$ & 0.78 \\
\hline & $A G$ & $88.94(24.24)$ & $94.51(23.63)$ & $-3.89(-15.25$ to 7.46$)$ & 0.49 \\
\hline & GG & $89.69(28.02)$ & $88.13(25.75)$ & $1.75(-11.48$ to 14.99$)$ & 0.79 \\
\hline$P^{\ddagger}$ & & 0.85 & 0.49 & & \\
\hline \multirow[t]{3}{*}{ Protein (g/day) } & $A A$ & $84.96(22.77)$ & $99.80(15.56)$ & $1.050(-59.55$ to 61.65$)$ & 0.96 \\
\hline & $A G$ & $98.67(20.62)$ & $87.77(15.54)$ & $7.55(-0.13$ to 15.22$)$ & 0.04 \\
\hline & GG & $87.90(21.74)$ & $88.75(17.62)$ & $-0.60(-8.71$ to 7.50$)$ & 0.88 \\
\hline$P^{\ddagger}$ & & 0.07 & 0.39 & & \\
\hline \multirow[t]{3}{*}{ Carbohydrate (g/day) } & $A A$ & $398.97(111.25)$ & $476.35(53.66)$ & $-73.33(-373.72$ to 227.06$)$ & 0.55 \\
\hline & $A G$ & $460.26(80.22)$ & $455.29(92.83)$ & $-13.55(-50.62$ to 23.51$)$ & 0.46 \\
\hline & GG & $408.06(92.58)$ & $418.51(63.02)$ & $-9.61(-42.35$ to 23.13$)$ & 0.55 \\
\hline$P^{\ddagger}$ & & 0.03 & 0.09 & & \\
\hline \multirow[t]{3}{*}{ Iron (mg/day) } & $A A$ & $20.44(4.34)$ & $24.812(4.11)$ & $-2.58(-16.33$ to 11.16$)$ & 0.64 \\
\hline & $A G$ & $24.93(6.48)$ & $23.10(5.49)$ & $0.48(-2.06$ to 3.02$)$ & 0.70 \\
\hline & GG & $21.44(4.86)$ & $22.41(4.72)$ & $-0.93(-3.05$ to 1.19$)$ & 0.38 \\
\hline$p^{\ddagger}$ & & 0.03 & 0.62 & & \\
\hline \multirow[t]{3}{*}{ Copper (mg/day) } & $A A$ & $2.05(0.55)$ & $2.37(0.29)$ & $-0.19(-1.70$ to 1.31$)$ & 0.75 \\
\hline & $A G$ & $2.44(0.53)$ & $2.37(0.56)$ & $-0.05(-0.28$ to 0.18$)$ & 0.64 \\
\hline & GG & $2.12(0.50)$ & $2.22(0.40)$ & -0.09 ( -0.30 to 0.12$)$ & 0.39 \\
\hline$P^{\ddagger}$ & & 0.03 & 0.39 & & \\
\hline \multirow[t]{3}{*}{ Vitamin E (mg/day) } & $A A$ & $12.67(8.53-21.93)$ & 16.79 (13.69-22.42) & - & 0.22 \\
\hline & $A G$ & 13.00 (10.09-17.18) & $14.70(11.30-17.82)$ & - & 0.34 \\
\hline & GG & $11.67(9.63-17.54)$ & 14.04 (11.24-17.97) & - & 0.33 \\
\hline$p^{\ddagger}$ & & 0.96 & 0.29 & & \\
\hline \multirow[t]{3}{*}{ Vitamin C (mg/day) } & $A A$ & $81.92(47.27-249.34)$ & $118.56(90.91-151.10)$ & - & 0.14 \\
\hline & $A G$ & 126.91 (95.77-178.86) & $103.65(83.98-184.27)$ & - & 0.51 \\
\hline & GG & $123.22(73.77-137.46)$ & $121.90(94.37-163.71)$ & - & 0.39 \\
\hline$P^{\ddagger}$ & & 0.07 & 0.99 & & \\
\hline
\end{tabular}

Italic values are statistically significant at $\mathrm{P}<0.05$

Vitamin C intake is presented as median (percentile 25th-percentile 75th) and other as mean (SD)

+ P-value for analysis of co variance (ANCOVA) adjusted for confounding effects of age and gender

₹ $P$ value of vitamins $E$ and $C$ based on Kruskal-Wallis and otherwise based on one way ANOVA 
their study. Higher dietary iron consumption and especially heme-iron may play a role in the pathogenesis of NAFLD by increasing oxidative stress [41, 42]. Iwasa et al. [43] and Yamamoto et al. [44] have demonstrated that lower intakes of calorie and iron lead to reduce visceral fat, liver enzymes and ferritin in patients with chronic liver disease and nonalcoholic fatty disease.

It seems that AG genotype of UCP2 is an important genetic predisposing factor of metabolic disease including obesity and T2DM $[24,45,46]$; in parallel of these observations, our study is the first study reported the gene-nutrient interactions between $-866 \mathrm{~A} / \mathrm{G}$ of UCP2 gene polymorphism and NAFLD.

Our NAFLD participants had non-significantly lower intake of antioxidants including vitamins $\mathrm{C}$ and $\mathrm{E}$. Previous reports also highlighted the poor antioxidant intakes in these patients; Musso et al. [47] reported a low dietary ascorbic acid and tocopherol intake in patients with non-alcoholic steato-hepatitis. These findings were also been supported in the study of Erhardt et al. [48] reporting reduced tocopherol and carotenoid consumption as dietary antioxidants compounds in patients with NASH compared to healthy group. The non-significance threshold of our findings might be attributed to the difference in the stage of disease compared with these two studies.

\section{Conclusions}

The present study reported a high prevalence of metabolic abnormalities in NAFLD patients. In addition, NAFLD patients with AG genotype consumed more calories, protein, carbohydrate, iron and copper and low amounts of vitamin $\mathrm{C}$ and $\mathrm{E}$ in their usual diet. However, statistical significant differences were only observed in protein, iron and copper consumption among NAFLD group. It is clear that dietary modification is the easiest and even the most efficient way to reduce chronic disease risk factors $[49,50]$. This is the first study comparing nutritional intakes according to UCP2 -866G/A gene polymorphism in patients with NAFLD; however several limitations of the current study should also be addressed; first, the case control design of the study has not potential to address cause and effect relationship between variables. Second, we did not evaluate the markers of oxidative stress in our study. Further studies with larger sample size and interventional designs are needed to determine the association of dietary compounds and different UCP2 genotypes in nonalcoholic fatty liver disease.

\section{Abbreviations}

ALT: alanine aminotransferase; ANCOVA: analysis of co-variance; AST: aspartate aminotransferase; BMI: body mass index; BIA: bioelectrical impedance analysis; FFM: fat free mass; FM: fat mass; FFQ: food frequency questionnaire; HC: hip circumference; HDL-C: high density lipoprotein cholesterol; IPAQ: international physical activity questionnaire; LDL-C: low density lipoprotein cholesterol;
MET: metabolic equivalent; NAFLD: non-alcoholic fatty liver disease; NASH: nonalcoholic steatohepatitis; NHANES: National Health and Nutrition Examination Survey; SNP: single nucleotide gene polymorphism; TC: total cholesterol; TG: triglyceride; T2DM: type 2 diabetes mellitus; UCP: uncoupling protein; US: ultrasonography; WC: waist circumference; WHR: waist to hip ratio.

\section{Authors' contributions}

MAF supervised the project, was involved in the designing and coordination and revised the article drafting. FM carried out the molecular genetic studies and write the first draft of the article, SF was involved in the genetic assays and MAJ helped in the statistical analysis. All authors read and approved the final manuscript.

\section{Author details}

${ }^{1}$ Nutrition Research Center, Department of Community Nutrition, School of Nutrition, Tabriz University of Medical Sciences, Tabriz, Iran. ${ }^{2}$ Drug Applied Research Center (DARC), Tabriz University of Medical Sciences, Tabriz, Iran. ${ }^{3}$ Road Traffic Injury Research Center, Tabriz University of Medical Sciences, Tabriz, Iran.

\section{Acknowledgements}

We thank all of the participants in the current study. We also thank Nutrition Research Center for providing laboratory facilities. Hereby we confirm that each coauthor participated in the work sufficiently and the authorship is as follows: Farhangi MA was involved in the conception, designing, supervising the project and revising the manuscript draft, Mohseni F participated in data collection, data analysis and wrote the first draft of the paper, Farajnia S has supervised the genetic assays and Asghari-Jafarabadi M performed the statistical analysis.

\section{Competing interests}

The authors declare that they have no competing interests.

Availability of data and supporting materials

The data and all of outputs of the current study are available for testing by reviewers and scientists wish to use them with kind full permission.

\section{Ethical approval}

The protocol of the study has been approved by the ethics committee of Tabriz University of Medical Science (Ethical approval 11013).

Funding

The study has been supported by a Grant from Tabriz University of Medical Sciences.

Received: 7 April 2016 Accepted: 2 June 2016

Published online: 14 June 2016

\section{References}

1. Abbasalizad Farhangi M, Alipour B, Jafarvand E, Khoshbaten M. Oral coenzyme Q10 supplementation in patients with nonalcoholic fatty liver disease: effects on serum vaspin, Chemerin, Pentraxin 3, insulin resistance and oxidative stress. Arch Med Res. 2014;45:589-95.

2. Rocha R, Cotrim HP, Carvalho FM, Siqueira AC, Braga H, Freitas LA. Body mass index and waist circumference in non-alcoholic fatty liver disease. J Hum Nutr Diet. 2005;18:365-70.

3. Adams LA, Lymp JF, Sauver JS, Sanderson SO, Lindor KD, Feldstein A, et al. The natural history of non-alcoholic fatty liver disease: a populationbased cohort study. Gastroenterology. 2005;129:113-21.

4. Browning JD, Szczepaniak LS, Dobbins R. Prevalence of hepatic steatosis in an urban population in the United States: impact of ethnicity. Hepatology. 2004;40:1387-95.

5. Lankarani Bagheri K, Ghaffarpasand F, Mahmoodi M, Lotfi M, Zamiri N, Heydari ST, et al. Non alcoholic fatty liver disease in southern Iran: a population based study. Hepat Mon. 2013;13:9248.

6. Weiß J, Rau M, Geier A. Non-alcoholic fatty liver disease: epidemiology, clinical course, investigation, and treatment. Dtsch Arzteblatt Int. 2014;111:447-52. 
7. Sharifi N, Mahdavi R, Ebrahimi-Mameghani M. Perceived barriers to weight loss programs for overweight or obese women. HPP. 2013;3:11-22.

8. Arefhosseini SR, Ebrahimi-Mameghani M, Naeimi AF, Khoshbaten M, Rashid J. Lifestyle modification through dietary intervention: health promotion of patients with non-alcoholic fatty liver disease. HPP. 2011;1:147-54.

9. Lyon DE, Mohanraj L, Kelly DL, Jr ER. Health promoting life-style behaviors and systemic inflammation in African American and Caucasian women prior to chemotherapy for breast cancer. HPP. 2014;4:18-26.

10. Kalafati IP, Borsa D, Dedoussis GVZ. The genetics of nonalcoholic fatty liver disease: role of diet as a modifying factor. Curr Nutr Rep. 2014;3:223-32.

11. Asrih M, Jornayvaz FR. Diets and nonalcoholic fatty liver disease: the good and the bad. Clin Nutr. 2014;33:186-90.

12. Hashemi kani A, Alavian SM, Esmaillzadeh A, Adibi P, Azadbakht L. Dietary quality indices and biochemical parameters among patients With non alcoholic fatty liver disease (NAFLD). Hepat Mon. 2013;13:1-10.

13. Le KA, Bortolotti M. Role of dietary carbohydrates and macronutrients in the pathogenesis of nonalcoholic fatty liver disease. Curr Opin Clin Nutr Metab Care. 2008;11:477-82.

14. AbbasalizadFarhangi M, Keshavarz SA, Eshraghian M, Ostadrahimi A, Saboor-Yaraghi AA. Vitamin A supplementation, serum lipids, liver enzymes and $\mathrm{C}$-reactive protein concentrations in obese women of reproductive age. Ann Clin Biochem. 2013;50:25-30.

15. Aigner E, Weiss G, Datz Ch. Dysregulation of iron and copper homeostasis in nonalcoholic fatty liver. World J Hepatol. 2015;7:177-88.

16. Aigner E, Strasser M, Haufe H, Sonnweber Th, Hohla F, Stadlmayr A, et al. A role for low hepatic copper concentrations in nonalcoholic fatty liver disease. Am J Gastroenterol. 2010;105:1978-85.

17. Aigner E, Theurl I, Haufe H, Seifert M, Hohla F, Scharinger L, et al. Copper availability contributes to iron perturbations in human nonalcoholic fatty liver disease. Gastroenterology. 2008;135:680-8.

18. Oliveira CP, Gayotto LC, Caroline Tatai, Della N, Bianca I, Lima ES, et al. Vitamin $C$ and vitamin $E$ in prevention of nonalcoholic fatty liver disease (NAFLD) in choline deficient diet fed rats. Nutr J. 2003;2:1-5.

19. Papandreou $D$, Andreou E. Role of diet on non-alcoholic fatty liver disease: an updated narrative review. World. J Hepatol. 2015;7:575-82.

20. Solga S, Alkhuraishe AR, Clark JM, Torbenson M, Greenwald A, Diehl AM, et al. Dietary composition and nonalcoholic fatty liver disease. Dig Dis Sci. 2004;49:1578-83.

21. Santoro N, Savoye M, Kim G, Marotto K, Shaw MM, Pierpont B, et al. Hepatic fat accumulation is modulated by the interaction between the rs 738409 variant in the PNPLA3 gene and the dietary omega6/omega3 PUFA intake. PLoS ONE. 2012;7:e37827.

22. Schmitz G, Ecker J. The opposing effects of $n-3$ and $n-6$ fatty acids. Prog Lipid Res. 2008;47:147-55.

23. Dalgaard LT. Genetic variance in uncoupling protein 2 in relation to obesity, type 2 diabetes, and related metabolic traits: focus on the functional -866G >A promoter variant (rs659366). J Obes. 2011;2011:1-12.

24. D'Adamo M, Perego L, Cardellini M, Marini M, Frontoni SF, Andreozzi F, et al. The -866A/A genotype in the promoter of the human uncoupling protein 2 gene is associated with insulin resistance and increased risk of type 2 diabetes. Diabetes. 2014;2004(53):1905-10.

25. Donadelli M, Dando I, Fiorini C, Palmieri M. UCP2 a mitochondrial protein regulated at multiple levels. Cell Mol Life Sci. 2014;71:1171-90.

26. Baffy G. Uncoupling protein-2 and non-alcoholic fatty liver disease. Front Biosci. 2005;10:2082-96.

27. Kelishadi R, Ardalan G, Gheiratmand R, Gouya MM, Razaghi EM, Delavari $A$, et al. Association of physical activity and dietary behaviours in relation to the body mass index in a national sample of Iranian children and adolescents: CASPIAN Study. Bull World Health Organ. 2007;85:19-26.

28. Kelishadi R, Rabiei K, Khosravi A, Famouri F, Sadeghi M, Rouhafza H, et al. Assessment of physical activity of adolescents in Isfahan. J Shahrekord Uni Med Sci. 2004;3:55-65.

29. Friedewald W, Levy RI, Fredrickson DS. Estimation of the concentration of low-density lipoprotein cholesterol in plasma, without use of the preparative ultracentrifuge. Clin Chem. 1972:18:499-502.

30. Grundy SM, Hansen B, Smith SC, Cleeman JI, Kahn RA. Clinical management of metabolic syndrome report of the American Heart Association/ National Heart, Lung, and Blood Institute/American Diabetes Association conference on scientific issues related to management. Circulation. 2004;109:551-6.
31. Delavari A, Forouzanfar MH, Alikhani S, Sharifian A, Kelishadi R. First nationwide study of the prevalence of the metabolic syndrome and optimal cutoff points of waist circumference in the Middle East the National Survey of risk factors for noncommunicable diseases of Iran. Diab Care. 2009:32:1092-7.

32. Abbasalizad Farhangi M, Jahangiry L, Mirinazhad M, Shojaeezade D, Montazeri A, Yaghoubi A. A web-based interactive lifestyle modification program improves lipid profile and serum adiponectin concentrations in patients with metabolic syndrome: the "Red Ruby"study. Int J Diabetes Dev Ctries 2015 (in press)

33. Mirmiran P. Hosseini Esfahani F, Mehrabi Y, Hedayati M, Azizi F. Reliability and relative validity of an FFQ for nutrients in the Tehran lipid and glucose study. Public Health Nutr. 2009;13:654-62.

34. Shu XO, Yang G, Jin F, Liu D, Kushi L, Wen W, et al. Validity and reproducibility of the food frequency questionnaire used in the Shanghai Women's Health Study. Eur J Clin Nutr. 2004;58:17-23.

35. Li YC, Li Cl, Lin WY, Liu CS, Hsu HS, Lee CC, et al. Percentage of body fat assessment using bioelectrical impedance analysis and dual-energy $\mathrm{X}$-ray absorptiometry in a weight loss program for obese or overweight Chinese adults. PLoS ONE. 2013;8:e58272.

36. Miller S, Dykes D, Polesky HA. Simple salting out procedure for extracting DNA from nucleated cells. Nucleic Acid Res. 1988:16:1215.

37. Zelber-Sagi Sh, Nitzan-Kaluski D, Goldsmith R, Webb M, Blendis L, Halpern $Z$, et al. Long term nutritional intake and the risk for non-alcoholic fatty liver disease (NAFLD): a population based study. J Hepatol. 2007:47:711-7.

38. Da Silva HE, Arendt BM, Noureldin SA, Therapondos G, Guindi M, Allard JP. A cross-sectional study assessing dietary intake and physical activity in Canadian patients with nonalcoholic fatty liver disease vs healthy controls. J Acad Nutr Diet. 2014:114:1181-94.

39. Amitesh A, Sourabh A, Vishal Sh. Cardiovascular risk factors in young patients of coronary artery disease: differences over a decade. J Cardiovasc Thorac Res. 2014;6:169-73.

40. Clark JM, Brancati FL, Diehl AM. The prevalence and etiology of elevated aminotransferase levels in the United States. Am J Gastroenterol. 2003;98:960-7.

41. Alla V, Bonkovsky H. Iron in nonhemochromatotic liver disorders. Semin Liver Dis. 2005;25(4):461-72

42. Yoshio S, Toshikazu Y, Takeshi O. Role of hepatic iron in non-alcoholic steatohepatitis. Hepatol Res. 2009;39:213-22.

43. Iwasa M, Hara N, Iwata K, Ishidome M, Sugimoto R, Tanaka H, et al. Restriction of calorie and iron intake results in reduction of visceral fat and serum alanine aminotransferase and ferritin levels in patients with chronic liver disease. Hepatol Res. 2010;40:1188-94.

44. Yamamoto T, Motoh I, Kazuko I, Kaito M, Konishi M, Adachi Y. Restriction of dietary calories, fat and iron improves non-alcoholic fatty liver disease. J Gastroenterol Hepatol. 2007:22:498-503.

45. Shen H, Qi L, Tai ES, Chew SK, Tan CE, Ordovas JM. Uncoupling protein 2 promoter polymorphism -866G/A, central adiposity, and metabolic syndrome in Asians. Obesity. 2006;14:656-61.

46. Srivastava N, Prakash J, Lakhan R, Agarwal CG, Plant DC, Mittal B. A common polymorphism in the promoter of UCP2 is associated with obesity and hyperinsulenemia in northern Indians. Mol Cell Biochem. 2010;337:293-8.

47. Musso G, Gambino R, De Michieli F, Cassader M, Rizzetto M, Durazzo M, et al. Dietary habits and their relations to insulin resistance and postprandial lipemia in nonalcoholic steatohepatitis. Hepatology. 2003;37:909-16.

48. Erhardt A, Stahl W, Sies H, Lirussi F, Donner A, Häussinger D. Plasma levels of vitamin $\mathrm{E}$ and carotenoids are decreased in patients with nonalcoholic steatohepatitis (NASH). Eur J Med Res. 2011;16:76-8.

49. Loktionov A. Common gene polymorphisms and nutrition: emerging links with pathogenesis of multifactorial chronic diseases (review). J Nutr Biochem. 2003;14:426-51.

50. Azizi H, Asadollahi K, Davtalab Esmaeili E, Mirzapoor M. Iranian dietary patterns and risk of colorectal cancer. HPP. 2015;5:72-80. 